\title{
Breast, cervical and colorectal cancer screening in adults with diabetes: a systematic review and meta-analysis
}

\author{
Dominika Bhatia $^{1}$ - Iliana C. Lega ${ }^{2} \cdot$ Wei $\mathrm{Wu}^{2} \cdot$ Lorraine L. Lipscombe $^{1,2}$
}

Received: 2 April 2019 / Accepted: 9 August 2019/Published online: 24 October 2019

(C) Springer-Verlag GmbH Germany, part of Springer Nature 2019

\begin{abstract}
Aims/hypothesis Individuals with diabetes are at increased risk of developing and dying from cancer. Evidence-based guidelines recommend universal screening for breast, cervical and colorectal cancer; however, evidence on the uptake of these tests in individuals with diabetes is mixed. We conducted a meta-analysis to quantify the association between diabetes and participation in breast, cervical and colorectal cancer screening.

Methods MEDLINE, EMBASE and CINAHL were searched systematically for publications between 1 January 1997 and 18 July 2018. The search was supplemented by handsearching of reference lists of the included studies and known literature reviews. Abstracts and full texts were assessed in duplicate according to the following eligibility criteria: study conducted in the general population; diabetes included as a predictor vs a comparison group without diabetes; and breast (mammography), cervical (Papanicolaou smear) or colorectal (faecal and endoscopic tests) cancer screening uptake included as an outcome. Random-effects meta-analyses were performed using the most-adjusted estimates for each cancer site.

Results Thirty-seven studies ( 25 cross-sectional, 12 cohorts) were included, with 27 studies on breast, 19 on cervical and 18 on colorectal cancer screening. Having diabetes was associated with significantly lower likelihood of breast (adjusted OR 0.83 [95\% CI 0.77, 0.90]) and cervical (OR 0.76 [95\% CI 0.71, 0.81]) cancer screening, relative to not having diabetes. Colorectal cancer screening was comparable across groups with and without diabetes (OR 0.95 [95\% CI 0.86, 1.06]); however, women with diabetes were less likely to receive a colorectal cancer screening test than women without diabetes (OR 0.86 [95\% CI 0.77, 0.97]).

Conclusions/interpretation Our findings suggest that women with diabetes have suboptimal breast, cervical and colorectal cancer screening rates, compared with women without diabetes, although the absolute differences might be modest. Given the increased risk of cancer in this population, higher quality prospective evidence is necessary to evaluate the contribution of diabetes to cancer screening disparities in relation to other patient-, provider- and system-level factors.
\end{abstract}

Registration PROSPERO registration ID CRD42017073107.

Electronic supplementary material The online version of this article (https://doi.org/10.1007/s00125-019-04995-7) contains peer-reviewed but unedited supplementary material, which is available to authorised users.

Lorraine L. Lipscombe

lorraine.lipscombe@wchospital.ca

1 Institute of Health Policy, Management and Evaluation, Dalla Lana School of Public Health, University of Toronto, Toronto, ON, Canada

2 Women's College Research Institute, Women's College Hospital, 76 Grenville Street, Toronto, ON M5S 1B2, Canada
Keywords Breast cancer - Cancer screening - Cervical cancer . Colorectal cancer $\cdot$ Diabetes management $\cdot$ Diabetes mellitus . Healthcare barriers · Healthcare disparities · Meta-analysis . Systematic review

Abbreviations
$\begin{array}{ll}\text { FIT } & \text { Faecal immunochemical test } \\ \text { FOBT } & \text { Faecal occult blood test } \\ \text { NOS } & \text { Newcastle-Ottawa Scale } \\ \text { Pap } & \text { Papanicolaou } \\ \text { PR } & \text { Prevalence ratio } \\ \text { RCT } & \text { Randomised controlled trial }\end{array}$




\section{Research in context}

\section{What is already known about this subject?}

- Individuals with diabetes are at increased risk of developing and dying from cancer

- Evidence-based guidelines recommend routine universal screening for breast, cervical and colorectal cancer

- Current evidence reviews suggest possible cancer screening disparities in patients with chronic disease; however, the uptake of cancer screening tests in individuals with diabetes is unclear

What is the key question?

- What is the effect of diabetes on the uptake of recommended routine screening for breast, cervical and colorectal cancer, compared with not having diabetes?

What are the new findings?

- Women with diabetes were significantly less likely to receive breast and cervical cancer screening than women without diabetes

- Women with diabetes were also less likely to be screened for colorectal cancer than women without diabetes, with no such difference in men

- Absolute differences might be modest and the included studies had high heterogeneity, low methodological quality and showed a risk of publication bias

\section{How might this impact on clinical practice in the foreseeable future?}

- Suboptimal cancer screening rates in women with diabetes may be putting them at risk of poorer cancer outcomes. Higher quality prospective methods are needed to evaluate the contribution of diabetes to cancer screening disparities; population-based and targeted approaches are needed for improving cancer screening uptake and reducing the burden of diabetes management in this population

\section{Introduction}

Cancer is a leading cause of death worldwide, with rapidly growing incidence and mortality rates [1]. Diabetes has been associated with $30 \%$ higher incidence of certain cancers [2-4] and $40 \%$ higher mortality after cancer diagnosis [5]. Individuals with diabetes are also more likely to be diagnosed with advanced-stage tumours [6-8] and to experience greater toxicity during treatment $[9,10]$, leading to more conservative regimens $[11,12]$. Beyond shared risk factors, such as socioeconomic status [13], lifestyle behaviours [14-17] and being overweight or obese [18-20], diabetes is hypothesised to be causally related to cancer through tumorigenic effects of insulin resistance and hyperinsulinaemia [21-23].

Screening for breast, cervical and colorectal cancer has been associated with up to 33\% [24], 70\% [25] and 37\% [26] reduction, respectively, in cancer-specific deaths. Breast cancer screening detects early-stage tumours, which have a better prognosis [24], while cervical and colorectal cancer screening also detect pre-malignant lesions $[25,26]$. Evidence-based guidelines recommend universal screening with mammography for breast cancer, Papanicolaou ('Pap') smear for cervical cancer, and faecal and endoscopic tests for colorectal cancer [27-34]. Many jurisdictions have also implemented organised programmes to deliver populationwide screening [35-40].

The importance of cancer screening and early detection is especially salient for individuals with diabetes. Previous studies have suggested that people with diabetes may experience poorer preventive care due to the competing priorities of chronic disease management [41-47], which place a substantial burden on patients and their healthcare teams [42]. The extent to which diabetes impacts the receipt of recommended cancer screenings, however, is unclear. In this systematic review and meta-analysis, we aimed to quantify the association between diabetes and breast, cervical and colorectal cancer screening participation.

\section{Methods}

Data sources We followed the Preferred Reporting Items for Systematic Reviews and Meta-Analyses (PRISMA) [48, 49] and the Meta-analysis of Observational Studies in Epidemiology (MOOSE) [50] guidelines (see electronic supplementary material [ESM] Checklists 1 and 2), and used a protocol to guide the review $[51,52]$ (PROSPERO: CRD42017073107). We developed an electronic search 
strategy in consultation with a public health information specialist and searched MEDLINE (Ovid), EMBASE (Ovid) and CINAHL (EBSCO) between 1 January 1997 and 18 July 2018 for English-language studies in adults (ESM Table 1). To ensure saturation, we reviewed reference lists of the included studies and known literature reviews [53-55]. Duplicates were removed using the Bramer algorithm, validated for use with EndNote reference management software (Version X7; Thompson Reuters, USA) [56].

Selection process and eligibility criteria Titles were screened by one reviewer (DB). To verify the quality of the screening process, the abstracts of a random sample of the excluded titles $(5 \%)$ were reviewed. Abstracts and full texts of the included articles were assessed for eligibility in duplicate by two independent reviewers (DB, WW). Inter-rater reliability was assessed using Cohen's K statistic, reflecting agreement beyond that attributable to chance [57]. Disagreements were settled through discussion and involvement of a third independent reviewer (IL). Study eligibility was defined using the following PECO (population, exposure, comparison group, outcome) criteria: (1) study was conducted in the general population; (2) study included diabetes as a predictor; (3) study included a comparison group without diabetes and (4) study reported breast, cervical or colorectal cancer screening uptake as an outcome. We excluded studies conducted in special populations ineligible for routine screening, along with case reports or series, commentaries, dissertations and conference abstracts.

Data abstraction and quality assessment Data were abstracted by one reviewer (DB) and critical appraisal was performed in duplicate by two independent reviewers (DB, WW). Disagreements were resolved by discussion and involvement of a third independent reviewer (IL). We used the Cochrane Handbook for Systematic Reviews-recommended NewcastleOttawa Scale (NOS) to evaluate the quality of observational studies $[57,58]$, including the secondary analysis of one randomised controlled trial (RCT) [59]. The NOS allocates up to 9 points to studies according to three quality domains: selection of the study groups; comparability of the groups and ascertainment of the outcome. A modified NOS was used for crosssectional studies [60]. The scoring of the 'comparability' criterion can be customised by specifying important covariates that studies should control for. Controlling for age and personal or family history of cancer was deemed to be particularly important due to the influence of these factors on screening recommendations' risk categories [27-34]. Publication bias was assessed by visually inspecting funnel plots [57].

Meta-analysis We performed random-effects meta-analyses to obtain summary effects for breast, cervical and colorectal cancer screening uptake. The random-effects approach assumes the existence of a distribution of distinct (yet related) exposure effects, rather than a single true effect, and thus reports the average effect of the exposure on the outcome [57]. Studies that reported an adjusted OR or prevalence ratio (PR) and a 95\% CI for receipt of a screening test in individuals with diabetes relative to those without were combined using the DerSimonian-Laird inverse variance method, which assigns weights to individual estimates based on their precision level $[57,61]$. Although PRs and ORs indicate the same directionality of effect in cross-sectional studies of non-rare outcomes, such as cancer screening, ORs may overestimate the strength of the association compared with PRs [62-64]. Since only two studies (one on breast cancer screening [65] and one on colorectal cancer screening [66]) reported PRs and their exclusion in sensitivity analyses did not meaningfully modify findings (data not shown), a decision was made to combine ORs and PRs together. Only the most-adjusted estimates were pooled to minimise confounding $[67,68]$. If studies reported the likelihood of not screening [65] or used diabetes as a reference group [59], the reciprocal of the effect estimate was pooled in the meta-analyses, as ORs are mathematically symmetrical [69]. If studies reported multiple unique ORs, they were entered separately in the meta-analyses. In studies with overlapping groups of participants, we chose the most representative estimate [65] or calculated the weighted average [70].

Heterogeneity was assessed using the $I^{2}$ statistic, describing the results' variability attributable to study heterogeneity, rather than chance [57]. We explored heterogeneity through subgroup analyses by study design, quality rating (high quality $>6$ points on NOS) [58] and setting, provided at least three unique estimates were available. Since most studies were conducted in the USA, subgroup analyses by setting were dichotomised into USA and non-USA studies. For studies on colorectal cancer screening, we performed subgroup analyses by type of screening test and sex of participants. Data were analysed using Cochrane Review Manager (RevMan) software (version 5.3; Copenhagen, Denmark).

\section{Results}

Cohen's K statistic for all duplicate-screened sections was 0.78 , reflecting excellent agreement between reviewers [57].

Characteristics of included studies Our search yielded 5200 unique records, of which 37 met the inclusion criteria (ESM Fig. 1). Individual study characteristics are presented in Table 1 and aggregate study characteristics in Table 2 (additional detail in ESM Table 2). Nine studies examined breast cancer screening [65, 71-78], two examined cervical cancer screening [79, 80], and eight examined colorectal cancer screening alone [59, 65, $66,70,81-85]$; eight studies examined both breast and cervical cancer screening [86-93], one examined breast and colorectal cancer screening [94], and nine examined all three cancer screenings [95-103]. All studies were observational, with 25 crosssectional $[65,70,77-80,82-85,87-93,95-100,102,103]$ and 


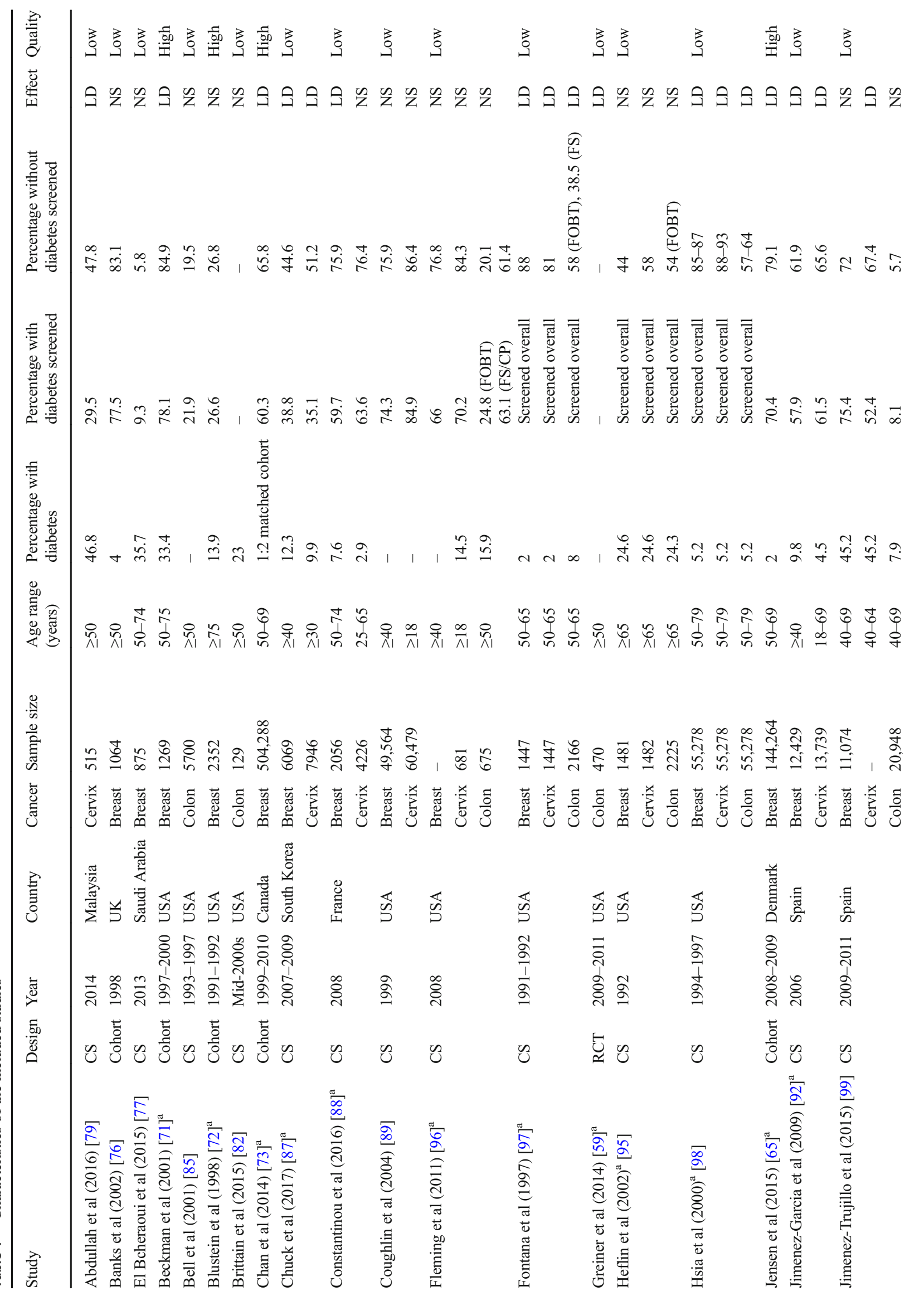




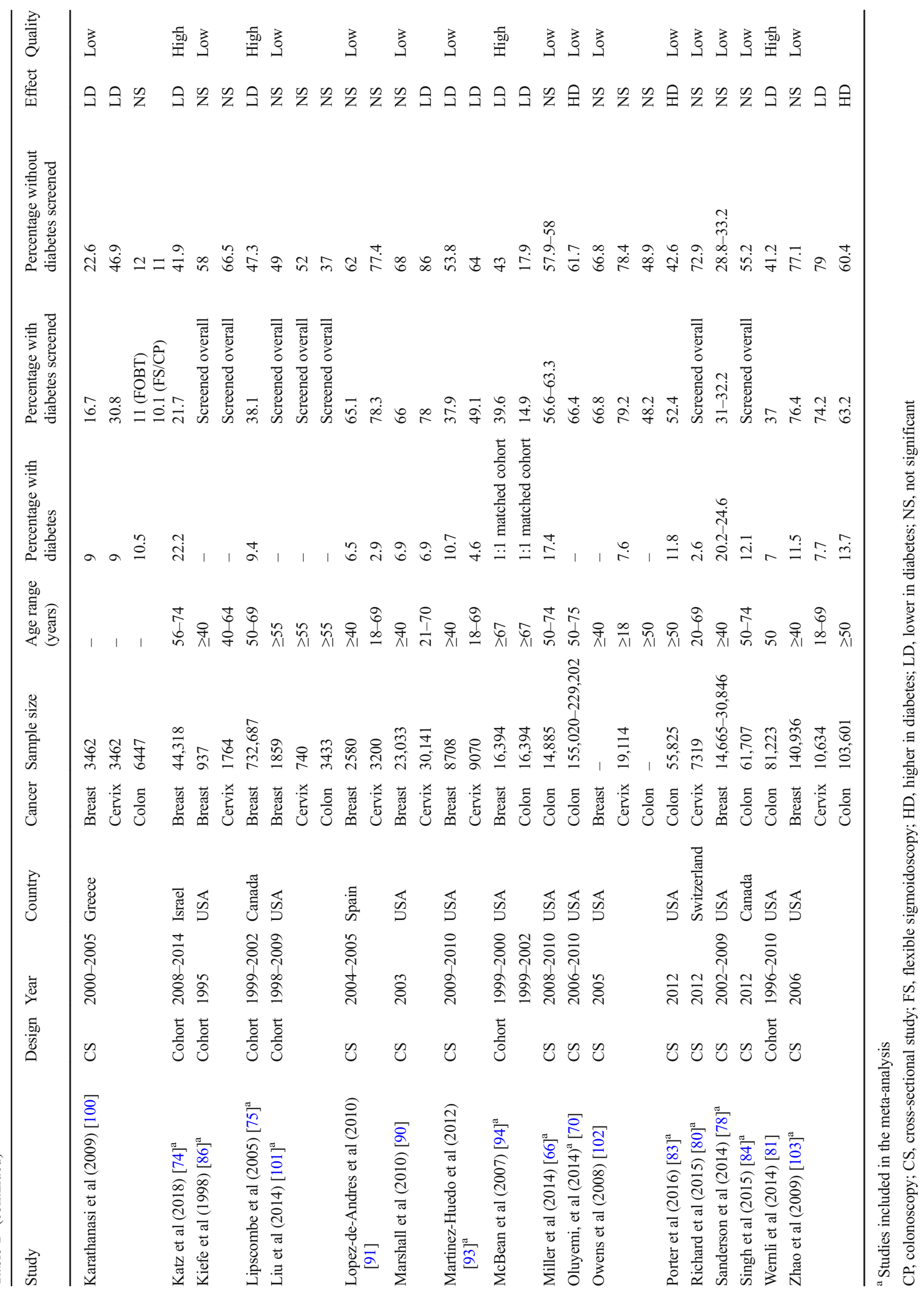


Table 2 Aggregate characteristics of the included studies by cancer screening site

\begin{tabular}{|c|c|c|c|c|c|c|}
\hline \multirow[t]{2}{*}{ Study characteristic } & \multicolumn{2}{|c|}{ Breast cancer screening } & \multicolumn{2}{|c|}{ Cervical cancer screening } & \multicolumn{2}{|c|}{ Colorectal cancer screening } \\
\hline & $\begin{array}{l}\text { In meta-analysis } \\
\text { (19 studies) }\end{array}$ & $\begin{array}{l}\text { Not in meta- } \\
\text { analysis ( } 8 \text { studies) }\end{array}$ & $\begin{array}{l}\text { In meta-analysis } \\
\text { (12 studies) }\end{array}$ & $\begin{array}{l}\text { Not in meta- } \\
\text { analysis ( } 7 \text { studies) }\end{array}$ & $\begin{array}{l}\text { In meta-analysis } \\
\text { (12 studies) }\end{array}$ & $\begin{array}{l}\text { Not in meta- } \\
\text { analysis (6 studies) }\end{array}$ \\
\hline \multicolumn{7}{|l|}{ Study design } \\
\hline Cross-sectional & $10(52.6)$ & $7(87.5)$ & $10(83.3)$ & $7(100)$ & $9(75)$ & $5(83.3)$ \\
\hline Cohort & $9(47.4)$ & $1(12.5)$ & $2(16.7)$ & - & $3(25)$ & $1(16.7)$ \\
\hline \multicolumn{7}{|l|}{ Data sources } \\
\hline Self-report & $10(52.6)$ & $7(87.5)$ & $10(83.3)$ & $7(100)$ & $9(75)$ & $5(83.3)$ \\
\hline Admin. claims & $6(31.6)$ & $1(12.5)$ & - & - & $1(8.3)$ & $1(16.7)$ \\
\hline Medical records & $3(15.8)$ & - & $2(16.7)$ & - & $2(16.7)$ & - \\
\hline \multicolumn{7}{|l|}{ Screening interval } \\
\hline$<1$ year & - & $1(12.5)$ & - & - & $1(8.3)$, all tests & - \\
\hline $1-3$ years $^{\mathrm{a}}$ & $19(100)$ & $7(87.5)$ & $12(100)$ & $6(85.7)$ & 8 (66.7), faecal & $3(50)$, faecal \\
\hline $3-5$ years & - & - & - & - & 3 (25), all tests & 1 (16.7), all tests \\
\hline $5-10$ years & - & - & - & - & 10 (83.3), Endo & 2 (33.3), Endo \\
\hline Ever & - & - & - & $1(14.3)$ & - & 2 (33.3), Endo \\
\hline \multicolumn{7}{|l|}{ Screening start age } \\
\hline 18-24 years & - & - & $5(41.7)$ & $4(57.1)$ & - & - \\
\hline $25-30$ years & - & - & $2(16.7)$ & - & - & - \\
\hline $40-45$ years & $7(36.8)$ & $5(62.5)$ & $1(8.3)$ & $1(14.3)$ & - & $1(16.7)$ \\
\hline $50-55$ years & $9(47.4)$ & $2(25)$ & $3(25)$ & $1(14.3)$ & $10(83.3)$ & $4(66.7)$ \\
\hline$>65$ years & $3(15.8)$ & - & $1(8.3)$ & - & $2(16.7)$ & - \\
\hline Not reported & - & $1(12.5)$ & - & $1(14.3)$ & - & $1(16.7)$ \\
\hline \multicolumn{7}{|l|}{ Screening end age } \\
\hline 64-69 years & $4(21)$ & $1(12.5)$ & $8(66.7)$ & $2(28.6)$ & $1(8.3)$ & $1(16.7)$ \\
\hline 70-79 years & $4(21)$ & $1(12.5)$ & $1(8.3)$ & $1(14.3)$ & $4(33.3)$ & - \\
\hline No upper age limit & $11(57.9)$ & $5(62.6)$ & $3(25)$ & $3(42.8)$ & $7(58.3)$ & $4(66.7)$ \\
\hline Not reported & - & $1(12.5)$ & - & $1(14.3)$ & - & $1(16.7)$ \\
\hline \multicolumn{7}{|l|}{ Screening programme } \\
\hline Organised & $8(42.1)$ & $3(37.5)$ & $2(16.7)$ & $2(28.6)$ & $1(8.3)$ & $2(33.3)$ \\
\hline Opportunistic & - & $2(25)$ & $3(25)$ & $2(28.6)$ & - & $1(16.7)$ \\
\hline Not reported & $11(57.9)$ & $3(37.5)$ & $7(58.3)$ & $3(42.8)$ & $11(91.7)$ & $3(50)$ \\
\hline \multicolumn{7}{|l|}{$\begin{array}{l}\text { Screening modality } \\
(\mathrm{CRC} \text { only })^{\mathrm{b}}\end{array}$} \\
\hline $\begin{array}{l}\text { Faecal test: FOBT or } \\
\text { FIT }\end{array}$ & - & - & - & - & $12(100)$ & $5(83.3)$ \\
\hline Endoscopy: FS or CP & - & - & - & - & $11(91.7)$ & $5(83.3)$ \\
\hline Endoscopy: other ${ }^{\mathrm{c}}$ & - & - & - & - & $3(25)$ & $3(50)$ \\
\hline $\begin{array}{l}\text { Women-only sample } \\
\text { (CRC only) }\end{array}$ & - & - & - & - & $3(25)$ & $1(16.7)$ \\
\hline
\end{tabular}

Data show no. of studies (\% of column total)

a 1-3 years for breast cancer screening; 2-3 years for cervical cancer screening; 1-2 years for colorectal cancer screening

${ }^{\mathrm{b}}$ Screening modalities are not mutually exclusive across studies (i.e. a single study could report on multiple screening modalities)

${ }^{\mathrm{c}}$ Other endoscopic tests include double-contrast barium enema, proctoscopy and computed tomographic (CT) colonography

$\mathrm{CP}$, colonoscopy; CRC, colorectal cancer; Endo, endoscopy; FS, flexible sigmoidoscopy

12 cohort $[59,65,71-76,81,86,94,101]$ designs, including one RCT assessing the effect of diabetes on colorectal cancer screening completion independent of the intervention [59]. Over half of the studies were conducted in North America, with 21 studies from the USA $[59,66,70-72,78,81-83,85,86,89,90$, 94-98, 101-103] and three from Canada [73, 75, 84]. The remaining studies were from Europe [65, 76, 80, 88, 91-93, 99, 100], the Middle East [74, 77] and Asia [79, 87]. Sample sizes 
ranged from 129 to 732,687 individuals and the mean sample diabetes prevalence was $15.1 \%$ for breast, $9.7 \%$ for cervical and $12.4 \%$ for colorectal cancer screening.

Assessment of methodological quality Methodological quality varied across studies (ESM Table 3). Overall, only nine studies $[59,65,71-75,81,94]$ were rated as high quality ( $>6$ points) and all were cohort designs. Nearly all studies were conducted in large population-based samples. Over half of the cross-sectional studies did not justify their sample sizes $[70,77,78,83,85$, 87-90, 96-98, 100, 103], which poses a risk of underpowered analyses. Most cross-sectional surveys also had low response rates $[80,91,96,97]$ or did not report either the response rate or the characteristics of non-respondents $[66,70,78,83-85,87$, $89,90,92,93,95,98-100,102]$. Three cohort studies did not provide information on loss to follow-up [71, 86, 101], posing the risk of attrition bias. Six cohort studies had overlapping or ambiguous intervals over which diabetes and cancer screening status were determined $[71,72,74,76,86,101]$, which raises concerns around the exposure and outcome temporal order. Thirty-six studies controlled for either age or personal or family history of cancer [59, 65, 66, 70-89, 91-103] and 22 controlled for both [19-28, 30, 31, 35, 39, 40, 43, 44, 48, 50, 52, 54, 55].

Funnel plots for each cancer site indicate possible small study effects (ESM Figs. 2-4), suggesting that we cannot rule out the risk of publication bias. Low-precision studies showed lower screening participation in individuals with diabetes and a larger screening uptake gap between the groups, while higher-precision studies were closely and symmetrically distributed about the pooled effect size estimates.

Assessment of the exposure Diabetes status was self-reported in 26 studies [59, 66, 70, 72, 77-80, 82-85, 88-93, 95-100, 102, 103], of which 17 considered ever-diagnosis [66, 70, 72, 78, 80, $83,85,90,92,93,95-99,102,103]$, two considered current diagnosis $[88,100]$ and seven did not provide a look-back period $[59,77,79,82,84,89,91]$. The remaining studies defined diabetes up to 10 years before baseline using administrative data $[65,71,73,75,81,94]$, medical charts $[74,86,101]$, records of prescription medications [76] and records of direct physical and laboratory examinations performed at the time of survey administration [87]. Two self-reported [78, 88] and four administrative data definitions $[71,73,75,94]$ were independently validated by healthcare professionals against medical charts $[71,73,75,78$, 94] and responses to other survey questions [88].

Breast cancer screening Breast cancer screening with a bilateral mammogram was defined using self-report in 17 studies [77, 78, 87-93, 95-100, 102, 103], administrative claims in seven studies $[65,71-73,75,76,94]$ and medical records in three studies [74, $86,101]$. Most studies were conducted in age-eligible women and defined screening as receiving a mammogram within 13 years, which is consistent with clinical guidelines [27-30]
(Table 2). To minimise inclusion of non-screening mammograms, studies excluded women with a history of breast cancer $[65,71-75,78,88,95,101]$, any cancer $[94,97,100]$, mastectomy [71, 100, 101], recent abnormal mammogram [101] or mammogram performed after a recent breast cancer diagnosis [75]. Mammograms performed by invitation within organised programmes were considered as screening tests $[65,76,88]$.

The prevalence of breast cancer screening ranged from $9.3 \%$ to $78.1 \%$ in women with diabetes and from $5.8 \%$ to $84.9 \%$ in women without diabetes. Adjusted ORs for breast cancer screening were reported by 19 studies $[65,71-75,78$, 86-88, 92-98, 101, 103] (Fig. 1). The remaining studies only reported the proportions of women screened in each group, due to the descriptive focus of the studies $[76,89,90,99,100$, 102], non-significant bivariate associations between diabetes and screening [91], or statistical model selection procedures [77]. One descriptive study [100] and 12 of the 19 analytical studies found that breast cancer screening participation was significantly lower in women with diabetes $[65,71,73-75$, 87, 88, 92-94, 97, 98].

The pooled OR for breast cancer screening uptake in women with diabetes relative to those without was 0.83 (95\% CI 0.77 , $0.90 ; 19$ studies, 23 subgroups, $I^{2}=97 \%$ ) (Fig. 1). Heterogeneity was partially explained by study designs and quality ratings; however, the effect size estimate remained robust in subgroup analyses across these factors (ESM Table 4). The likelihood of breast cancer screening in women with diabetes relative to those without was lower in studies conducted outside of the USA compared with those conducted in the USA [71, 72, 78, 86, 94-98, 101, 103] (outside USA: 0.78 [95\% CI 0.69, 0.88], 8 studies, 8 subgroups, $I^{2}=99 \%$; in USA: 0.89 [95\% CI 0.84 , 0.96 ], 11 studies, 15 subgroups, $I^{2}=54 \%$ ).

Cervical cancer screening Cervical cancer screening was determined using self-report in 17 studies [79, 80, 87-93, 95-100, $102,103]$ and medical records in two studies [86, 101]. Consistent with clinical guidelines [31-33], most studies considered age-eligible women and defined screening as receipt of a Pap test within 2-3 years (Table 2). To approximate a screeneligible population, some studies excluded women with a history of cervical cancer [88, 95, 101], any cancer [97, 100], hysterectomy $[88,89,100,101]$, or a recent abnormal Pap test [101].

The prevalence of cervical cancer screening ranged from $29.5 \%$ to $84.9 \%$ in women with diabetes and from $46.9 \%$ to $86.4 \%$ in women without diabetes. Seven studies did not report adjusted estimates due to the descriptive focus of the studies $[89,90,99,100,102]$ or non-significant bivariate associations between diabetes and screening [79, 91]. Lower uptake of cervical cancer screening in women with diabetes was observed in four descriptive $[79,90,99,100]$ and six analytical studies [87, 92, 93, 97, 98, 103], while three descriptive $[89,91,102]$ and six analytical studies $[80,86,88$, $95,96,101]$ found non-significant differences. 


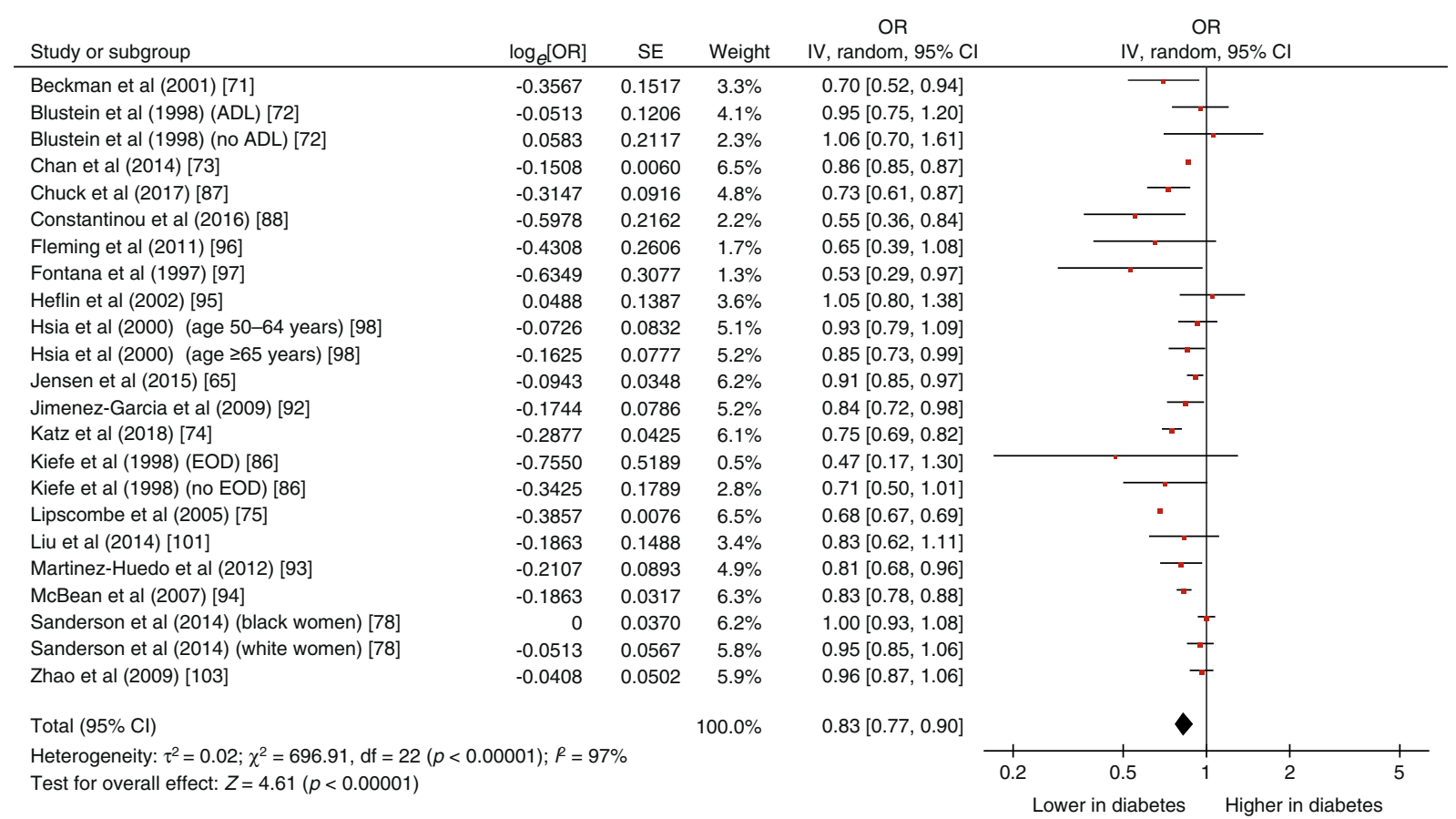

Fig. 1 Forest plot depicting breast cancer screening (mammography) in women with vs without diabetes. ADL, activities of daily living (subgroups by individuals with and without ADL limitations); EOD, end-organ damage (subgroups by individuals with and without EOD); IV, inverse variance

The pooled OR for cervical cancer screening uptake in women with diabetes relative to those without was 0.76 (95\% CI 0.71, 0.81; 12 studies, 14 subgroups), with low heterogeneity $\left(I^{2}=0 \%\right)$ (Fig. 2). This finding was robust across subgroup analyses by study design and setting (ESM Table 4). Subgroup analyses by quality rating could not be performed, as all studies on cervical cancer screening were rated as lower quality.

Colorectal cancer screening Colorectal cancer screening was determined using administrative data [81, 94] and medical records in two studies each [59, 101], and was self-reported in the remaining studies. Individuals were considered screened if they received a faecal or an endoscopic test, with faecal occult blood test (FOBT), flexible sigmoidoscopy and colonoscopy being the most frequently used tests. As recommended by clinical guidelines [34], screening intervals were $1-2$ years for faecal tests $[66,70,83-85,95,96,99-101,103]$ and 5-10 years for endoscopic tests [66, 70, 83-85, 96, 100, $101,103]$, and target populations included adults over the age of 50 (Table 2). To minimise inclusion of non-screening tests, studies excluded individuals with a history of colorectal cancer

\begin{tabular}{|c|c|c|c|c|c|c|c|c|}
\hline Study or subgroup & $\log _{e}[\mathrm{OR}]$ & SE & Weight & $\begin{array}{c}\text { OR } \\
\text { IV, random, } 95 \% \mathrm{Cl}\end{array}$ & \multicolumn{4}{|c|}{$\begin{array}{c}\text { OR } \\
\text { IV, random, } 95 \% \mathrm{Cl}\end{array}$} \\
\hline Chuck et al (2017) [87] & -0.3567 & 0.1324 & $6.5 \%$ & $0.70[0.54,0.91]$ & & & & \\
\hline Constantinou et al (2016) [88] & -0.3425 & 0.2441 & $1.9 \%$ & $0.71[0.44,1.15]$ & & & & \\
\hline Fleming et al (2011) [96] & -0.4780 & 0.3704 & $0.8 \%$ & $0.62[0.30,1.28]$ & & & & \\
\hline Fontana et al (1997) [97] & -0.4463 & 0.2527 & $1.8 \%$ & $0.64[0.39,1.05]$ & & & & \\
\hline Heflin et al (2002) [95] & -0.0619 & 0.1360 & $6.2 \%$ & $0.94[0.72,1.23]$ & & & & \\
\hline Hsia et al (2000) (age 50-64 years) [98] & -0.3711 & 0.1542 & $4.8 \%$ & $0.69[0.51,0.93]$ & & & & \\
\hline Hsia et al (2000) (age $\geq 65$ years) [98] & -0.2107 & 0.1282 & $7.0 \%$ & $0.81[0.63,1.04]$ & & & & \\
\hline Jimenez-Garcia et al (2009) [92] & -0.1985 & 0.1107 & $9.4 \%$ & $0.82[0.66,1.02]$ & & & & \\
\hline Kiefe et al (1998) (EOD) [86] & -0.6162 & 0.5605 & $0.4 \%$ & $0.54[0.18,1.62]$ & & & & \\
\hline Kiefe et al (1998) (no EOD) [86] & -0.3011 & 0.2000 & $2.9 \%$ & $0.74[0.50,1.10]$ & & & & \\
\hline Liu et al (2014) [101] & -0.3711 & 0.2911 & $1.4 \%$ & $0.69[0.39,1.22]$ & & & & \\
\hline Martinez-Huedo et al (2012) [93] & -0.3011 & 0.1070 & $10.0 \%$ & $0.74[0.60,0.91]$ & & - & & \\
\hline Richard et al (2015) [80] & 0 & 0.1820 & $3.5 \%$ & $1.00[0.70,1.43]$ & & & & \\
\hline Zhao et al (2009) [103] & -0.3147 & 0.0514 & $43.4 \%$ & $0.73[0.66,0.81]$ & & 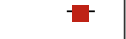 & & \\
\hline Total $(95 \% \mathrm{Cl})$ & & & $100.0 \%$ & $0.76[0.71,0.81]$ & & $\nabla$ & & \\
\hline \multirow{2}{*}{\multicolumn{2}{|c|}{$\begin{array}{l}\text { Heterogeneity: } \tau^{2}=0.00 ; \chi^{2}=8.21, \mathrm{df}=13(p=0.83) ; l^{2}=0 \% \\
\text { Test for overall effect: } Z=8.26(p<0.00001)\end{array}$}} & & & & $\frac{1}{0.2}$ & 0.5 & 2 & 5 \\
\hline & & & & & \multicolumn{4}{|c|}{ Lower in diabetes Higher in diabetes } \\
\hline
\end{tabular}

Fig. 2 Forest plot depicting cervical cancer screening (Pap smear) in women with vs without diabetes. EOD, end-organ damage (subgroups by individuals with and without EOD); IV, inverse variance 
$[59,66,81-83,95,101]$, any cancer $[94,97,100]$, inflammatory bowel disease $[59,81]$, colonic polyps or gastrointestinal bleeding [59], family history of colorectal cancer [59], hereditary polyposis/non-polyposis syndrome [59], colonoscopy before the age of 50 years [81], colectomy [81], colorectal cancer-related surgery [100], or recent abnormal screening results [101].

The prevalence of colorectal cancer screening ranged from $8.1 \%$ to $66.4 \%$ in individuals with diabetes and from $5.7 \%$ to $61.7 \%$ in individuals without diabetes. Twelve of the 18 studies reported adjusted ORs or PRs [59, 66, 70, 83, 84, 94-98, 101, 103]. The remaining studies had a descriptive focus $[85,99,100$, 102] or reported effect measures that could not be pooled with ORs [81, 82]. All four descriptive studies found that colorectal cancer screening was comparable between individuals with and studies were mixed, with three studies showing significantly greater likelihood of screening in diabetes [70, 83, 103], five studies showing significantly lower likelihood of screening in those with diabetes $[59,81,94,97,98]$ and six studies finding no significant difference $[66,82,84,95,96,101]$.

The pooled OR for colorectal cancer screening uptake in individuals with vs without diabetes was 0.95 (95\% CI 0.86, 1.06; 12 studies, 16 subgroups, $I^{2}=90 \%$ ) (Fig. 3). Heterogeneity was partially explained by differences in study design, participant sex and screening modalities (ESM Table 4). Cohort studies $0.70,0.86], I^{2}=0 \%$ ), though this represented only four subgroups from three studies $[59,94,101]$. Women with diabetes were less likely to be screened compared with women without diabetes (0.86 [95\% CI 0.77, 0.97]; 7 studies, 8 subgroups, $\left.I^{2}=85 \%\right)$, while among men, no such association was observed. The analysis was robust across screening modality subgroups (FOBT vs flexible sigmoidoscopy or colonoscopy). We could not perform subgroup analyses by quality rating or study setting, as only two without diabetes [85, 99, 100, 102]. The results of the analytical showed lower likelihood of screening in diabetes $(0.77$ [95\% CI

studies were rated to be of high quality $[59,94]$ and only one was conducted outside the USA [84]. Excluding each of these studies in sensitivity analyses did not meaningfully influence the results (ESM Table 4).

\section{Discussion}

Principal findings This systematic review and meta-analysis of 37 studies suggested that women with diabetes are significantly less likely to undergo recommended breast, cervical and colorectal cancer screening than women without diabetes, though the absolute differences might be modest. The findings were particularly robust for cervical cancer screening, with low heterogeneity across studies. Suboptimal cancer screening rates in women with diabetes may be putting them at risk of poorer cancer outcomes.

Strengths and limitations in relation to other studies To our knowledge, this is the first systematic review and metaanalysis of the effect of diabetes on cancer screening participation. Three literature reviews on cancer screening participation in adults with chronic comorbidities have been conducted to date, with mixed findings. A narrative review concluded that diabetes may negatively impact cancer screening uptake in elderly individuals [53], although the findings were based on only five studies conducted in the USA [71, 72, 86, 94, 95]. Another systematic review of seven studies found that chronic disease may be associated with increased likelihood of colorectal cancer screening, without specific inferences about diabetes [54]. Neither review performed a meta-analysis. A metaanalysis of 22 studies showed inconclusive evidence regarding the impact of composite comorbidity measures on breast and cervical cancer screening participation [55].

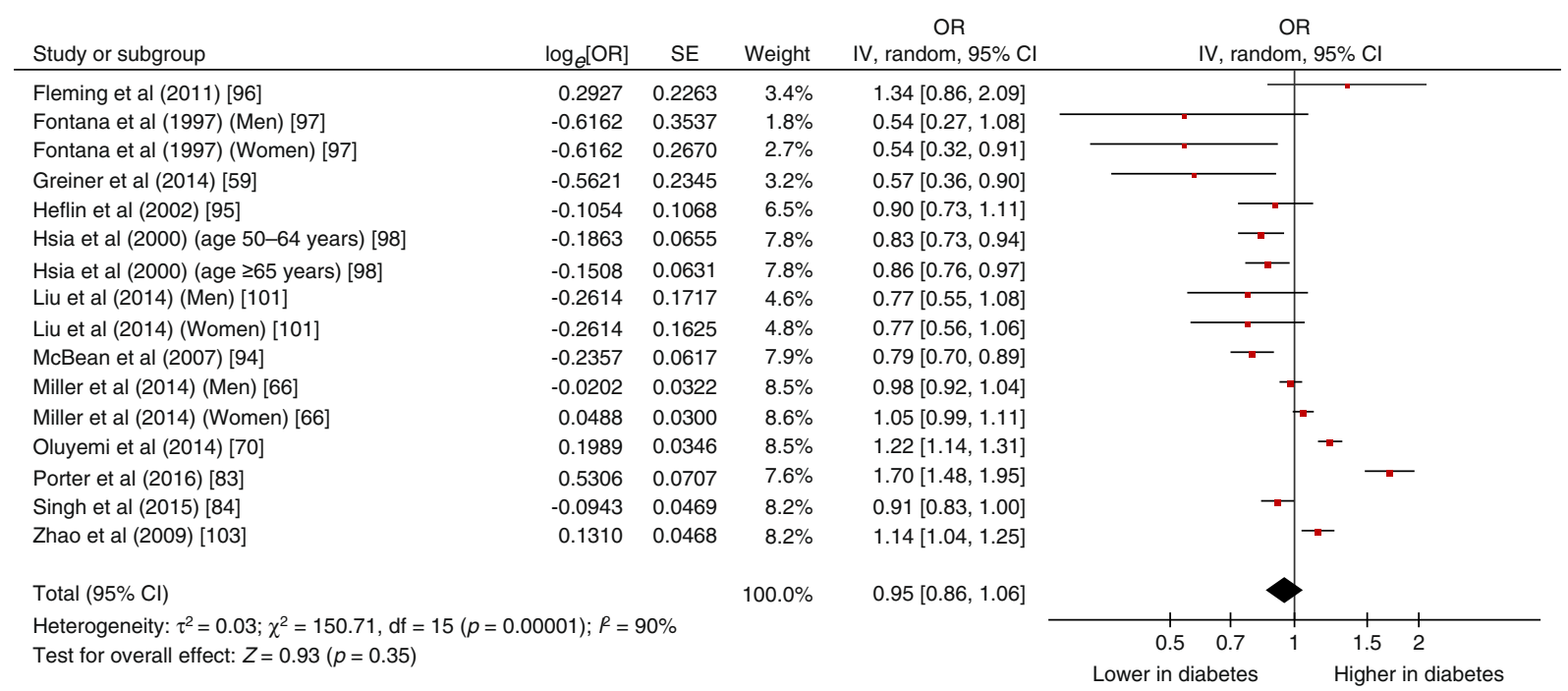

Fig. 3 Forest plot depicting colorectal cancer screening (faecal and endoscopic tests) in individuals with vs without diabetes. IV, inverse variance 
The strengths of our study include quantifying the specific effects of diabetes on all three recommended cancer screenings and a rigorous review process. Compared with prior research, our review resulted in a larger pool of eligible studies for each cancer site.

Our findings should be interpreted in light of a number of important limitations. First, most studies had low methodological quality ratings and the extent to which non-response bias and lack of power in cross-sectional studies and loss to followup in cohort studies may have affected our results is unclear. In addition, 25 of the 37 studies were cross-sectional, while another six studies had overlapping or unclear intervals in which the exposure and the outcome status were defined $[71,72,74$, $76,86,101]$. Many studies were therefore unable to determine whether the diabetes diagnosis preceded cancer screening participation, limiting our ability to infer causality. Nonetheless, since lifetime ('ever') diabetes diagnosis was considered in over half of these studies [66, 70, 72, 78, 80, 83, 85, 90, 92, 93, 95-99, 102, 103] while screening was established over intervals of under 10 years, instances of reversed exposureoutcome temporal sequences are likely to be few. Further, diabetes and outcome status were self-reported in most studies. While self-reported diabetes status has been shown to have high accuracy [104-108], cancer screening participation tends to be overestimated [109-111]. The true cancer screening participation gap in diabetes may thus be greater than that found.

Second, despite our efforts to only pool the most-adjusted effect estimates, meta-analyses of observational studies are particularly vulnerable to residual confounding $[67,68]$. Unexamined factors known to be associated with both diabetes status and cancer screening participation, such as socioeconomic status $[112,113]$, may thus underlie our findings. Interestingly, a Canadian study showed that diabetes was associated with lower mammographic breast cancer screening participation across all socioeconomic strata [73], suggesting that diabetes and socioeconomic status are distinct and independent barriers. The evidence on other possible confounding factors, including other comorbidities [55, 101], patient health and functional status [72], and patient preferences [114], is less clear. This residual confounding may also explain the high statistical heterogeneity that was observed in breast and colorectal cancer screening meta-analyses. In subgroup analyses, the heterogeneity was only partially accounted for by study designs, study quality ratings, healthcare systems (USA vs non-USA; breast cancer screening only), sex of participants (colorectal cancer screening only), and screening modalities (FOBT vs flexible sigmoidoscopy or colonoscopy; colorectal cancer screening only).

Third, we could not confidently rule out publication bias in our review. This is worth noting because, to gage betweenstudy variance, random-effects meta-analyses award relatively more weight to smaller studies than fixed effects metaanalyses [57], thus potentially biasing the result away from the null, should publication bias be present. However, in meta-analyses of observational studies, funnel plot asymmetry may also be attributed to residual confounding, methodological limitations and statistical heterogeneity, rather than publication bias alone [115].

Fourth, measures representing relative reductions in the likelihood of adequate screening, such as ORs, should be interpreted with caution, as absolute differences are likely to be more modest. While it is not possible to directly convert adjusted relative estimates into absolute ones [42], it is important to consider that diabetes may not be the most important, and thus actionable, determinant of cancer screening participation, compared with other characteristics of individuals.

Finally, it should be noted that our search was limited to studies written in English. However, according to a prior comprehensive review by evidence synthesis experts, the use of language restrictions is unlikely to result in systematic biases that could alter the interpretation of results [116].

Implications of findings and future directions The burden of diabetes management in primary care may contribute to lower cancer screening uptake among individuals with diabetes. It has been shown that as the number of guideline-recommended preventive services for which a person is eligible increases, the likelihood of their utilisation decreases [117]. Providing guideline-adherent chronic disease care also requires more consultation time than physicians have available per patient $[43,118-120]$, which may lead to prioritisation of diabetesrelated care over routine preventive care $[41,119,120]$. This is especially relevant for cervical cancer screening, as Pap tests are performed during office-based primary care visits, while breast and colorectal cancer screenings are performed outside of this setting. All tests nonetheless require physician orders, which may explain the modest reductions in both breast and colorectal cancer screening we found in women with diabetes.

Regional differences may also underlie our findings. We noted that the gap in breast cancer screening between women with and without diabetes was more pronounced in studies conducted outside the USA, including Canada [73, 75], France [88], Spain [92, 93], Denmark [65], Israel [74] and South Korea [87]. In contrast to the USA, all of these jurisdictions have universal healthcare systems and thus, more equitable access to preventive care. Since regular healthcare contact and health insurance status have shown to be independent predictors of cancer screening in the USA [98, 121], it is possible that individuals with diabetes receive more opportunistic screening than those without diabetes in non-universal healthcare settings due to increased healthcare contact. This may also explain our null findings for colorectal cancer screening, as all but one [84] of those studies were set in the USA. Sex-based differences in colorectal cancer screening participation in the present review are consistent with overall screening patterns in the USA, as women are less likely to 
undergo screening regardless of diabetes status [122]. Interestingly, research in other jurisdictions suggests the opposite trend, with women having higher colorectal cancer screening participation rates than men [123]. Our findings suggest that diabetes status may modify this trend in universal settings; however, more primary evidence in such settings is required. Other contextual factors, such as the overall population screening uptake rate and the presence of an organised screening programme, should also be examined.

Novel screening approaches may increase cancer screening uptake in groups presenting high healthcare burden and competing demands. The use of mail- and telephone-based invitations has been shown to improve first and repeat screening for all three cancers $[124,125]$. Direct mailing of self-screening kits, such as the faecal immunochemical test (FIT) for colorectal cancer [40, 126, 127] and human papilloma virus (HPV) test for cervical cancer [128-130], is associated with even greater screening uptake, particularly in under-screened populations [126-128, 131]. Emphasising colorectal cancer screening in women may be particularly important, as some women perceive colorectal cancer to mainly affect men [132, 133].

Beyond population-based interventions, targeted approaches may be particularly beneficial in individuals with diabetes. Shared-care between primary care physicians and diabetes specialists has been associated with better adherence to diabetes-related health services and higher likelihood of receiving breast and cervical cancer screening when compared with care by either practitioner alone [134]. Integrated diabetes management models may therefore improve attention to other recommended preventive health services by offloading diabetes care from primary care physicians. Supporting diabetes self-management may also yield better screening participation. Recent evaluations of patient navigator interventions in primary care have been associated with improved glycaemic control and appointment-keeping in patients with diabetes [135], as well as greater likelihood of colonoscopy attendance in the general population [136].

\section{Conclusion}

This systematic review and meta-analysis suggests that women with diabetes are significantly less likely to receive recommended breast, cervical and colorectal cancer screening than women without diabetes. Caution is warranted in interpreting these findings due to high study heterogeneity, low methodological quality of included studies, and risk of publication bias. Given the increased risk of cancer in this population, future studies should consider using higher quality prospective methods to evaluate the contribution of diabetes status to cancer screening disparities in relation to other patient-, provider- and system-level factors.
Acknowledgements We would like to thank V. Lui (Gerstein Science Information Centre, University of Toronto) for her guidance in the design of the electronic database search strategy. DB is supported by the Enid Walker Award in Women's Health Research from Women's College Hospital. LL is supported by the Diabetes Investigator Award from Diabetes Canada.

Contribution statement DB, IL and LL conceived and designed the study. WW provided methodological and statistical advice. IL and LL provided clinical guidance in interpreting the results. DB, WW and IL assessed citations for eligibility and risk of bias. DB was involved in data abstraction, synthesis and drafting of the first version of the manuscript. All authors contributed critically to subsequent revisions and approved the final manuscript. All authors had full access to the data in the study and take responsibility for the integrity of the data and accuracy of the data analysis. The corresponding author attests that all listed authors meet authorship criteria and that no others meeting the criteria have been omitted.

\section{References}

1. Bray F, Ferlay J, Soerjomataram I, Siegel RL, Torre LA, Jemal A (2018) Global cancer statistics 2018: GLOBOCAN estimates of incidence and mortality worldwide for 36 cancers in 185 countries. CA Cancer J Clin 68(6):394 424. https://doi.org/10.3322/ caac. 21492

2. Tsilidis KK, Kasimis JC, Lopez DS, Ntzani EE, Ioannidis JPA (2015) Type 2 diabetes and cancer: umbrella review of metaanalyses of observational studies. BMJ 350:g7607. https://doi. org/10.1136/bmj.g7607

3. Larsson SC, Mantzoros CS, Wolk A (2007) Diabetes mellitus and risk of breast cancer: a meta-analysis. Int J Cancer 121(4):856862. https://doi.org/10.1002/ijc.22717

4. Larsson SC, Orsini N, Wolk A (2005) Diabetes mellitus and risk of colorectal cancer: a meta-analysis. J Natl Cancer Inst 97(22): 1679-1687. https://doi.org/10.1093/jnci/dji375

5. Barone BB, Yeh HC, Snyder CF et al (2008) Long-term all-cause mortality in cancer patients with preexisting diabetes mellitus: a systematic review and meta-analysis. JAMA 300(23):2754. https://doi.org/10.1001/jama.2008.824

6. Lipscombe LL, Fischer HD, Austin PC et al (2015) The association between diabetes and breast cancer stage at diagnosis: a population-based study. Breast Cancer Res Treat 150(3):613620. https://doi.org/10.1007/s10549-015-3323-5

7. Peairs KS, Barone BB, Snyder CF et al (2011) Diabetes mellitus and breast cancer outcomes: a systematic review and meta-analysis. J Clin Oncol 29(1):40-46. https://doi.org/10.1200/JCO.2009. 27.3011

8. Fleming ST, Pursley HG, Newman B, Pavlov D, Chen K (2005) Comorbidity as a predictor of stage of illness for patients with breast cancer. Med Care 43(2):132-140. https://doi.org/10.1097/ 00005650-200502000-00006

9. Srokowski TP, Fang S, Hortobagyi GN, Giordano SH (2009) Impact of diabetes mellitus on complications and outcomes of adjuvant chemotherapy in older patients with breast cancer. J Clin Oncol 27(13):2170-2176. https://doi.org/10.1200/JCO. 2008.17.5935

10. Worndl E, Fung K, Fischer HD, Austin PC, Krzyzanowska MK, Lipscombe LL (2018) Preventable diabetic complications after a cancer diagnosis in patients with diabetes: a population-based cohort study. JNCI Cancer Spectr 2(1) pky008. Available from: https://academic.oup.com/jncics/article/doi/10.1093/jncics/ pky008/4995319, accessed 14 Nov 2018 
11. van de Poll-Franse LV, Houterman S, Janssen-Heijnen MLG, Dercksen MW, Coebergh JWW, Haak HR (2007) Less aggressive treatment and worse overall survival in cancer patients with diabetes: a large population based analysis. Int J Cancer 120(9): 1986-1992. https://doi.org/10.1002/ijc.22532

12. Gross CP, McAvay GJ, Guo Z, Tinetti ME (2007) The impact of chronic illnesses on the use and effectiveness of adjuvant chemotherapy for colon cancer. Cancer 109(12):2410-2419. https://doi. org/10.1002/cncr.22726

13. Clark AM, Raine K, Raphael D (2004) The American Cancer Society, American Diabetes Association, and American Heart Association joint statement on preventing cancer, cardiovascular disease, and diabetes: where are the social determinants? Diabetes Care 27(12):3024-3024. https://doi.org/10.2337/diacare.27.12. 3024

14. Davidson LE, Hudson R, Kilpatrick K et al (2009) Effects of exercise modality on insulin resistance and functional limitation in older adults: a randomized controlled trial. JAMA Intern Med 169(2):122-131

15. World Cancer Research Fund/American Institute for Cancer Research (2007) Food, nutrition, physical activity, and the prevention of cancer: a global perspective. AICR, Washington DC

16. Barclay AW, Petocz P, McMillan-Price J et al (2008) Glycemic index, glycemic load, and chronic disease risk - a meta-analysis of observational studies. Am J Clin Nutr 87(3):627-637. https://doi. org/10.1093/ajen/87.3.627

17. Sasco AJ, Secretan MB, Straif K (2004) Tobacco smoking and cancer: a brief review of recent epidemiological evidence. Lung Cancer 45:S3-S9. https://doi.org/10.1016/j.lungcan.2004.07.998

18. Renehan AG, Tyson M, Egger M, Heller RF, Zwahlen M (2008) Body-mass index and incidence of cancer: a systematic review and meta-analysis of prospective observational studies. Lancet 37(9612):569-578

19. Schienkiewitz A, Schulze MB, Hoffmann K, Kroke A, Boeing H Body mass index history and risk of type 2 diabetes: results from the European Prospective Investigation into Cancer and Nutrition (EPIC)-Potsdam study. Am J Clin Nutr 84(2):427-433. https:// doi.org/10.1093/ajen/84.2.427

20. Pischon T, Lahmann PH, Boeing H et al (2006) Body size and risk of colon and rectal cancer in the European prospective investigation into cancer and nutrition (EPIC). J Natl Cancer Inst 98(13): 920-931. https://doi.org/10.1093/jnci/djj246

21. Pisani P (2008) Hyper-insulinaemia and cancer, meta-analyses of epidemiological studies. Arch Physiol Biochem 114(1):63-70. https://doi.org/10.1080/13813450801954451

22. Goodwin PJ (2008) Insulin in the adjuvant breast cancer setting: a novel therapeutic target for lifestyle and pharmacologic interventions? J Clin Oncol 26(6):833-834. https://doi.org/10.1200/JCO. 2007.14.7132

23. Johnson JA, Carstensen B, Witte D et al (2012) on behalf of the Diabetes and Cancer Research Consortium. Diabetes and cancer (1): evaluating the temporal relationship between type 2 diabetes and cancer incidence. Diabetologia 55(6):1607-1618. https://doi. org/10.1007/s00125-012-2525-1

24. Gøtzsche PC, Jørgensen KJ (2013) Screening for breast cancer with mammography. Cochrane Database Syst Rev. Available from http://doi.wiley.com/10.1002/14651858.CD001877.pub5, accessed 14 November 2018

25. Peirson L, Fitzpatrick-Lewis D, Ciliska D, Warren R (2013) Screening for cervical cancer: a systematic review and meta-analysis. Syst Rev. 2:35. Available from: http://systematicreviewsjournal. biomedcentral.com/articles/10.1186/2046-4053-2-35, accessed 14 November 2018

26. Lin JS, Piper MA, Perdue LA et al (2016) Screening for colorectal cancer: updated evidence report and systematic review for the US
Preventive Services Task Force. JAMA 315(23):2576. https://doi. org/10.1001/jama.2016.3332

27. Siu AL, on behalf of the U.S. Preventive Services Task Force (2016) Screening for breast cancer: U.S. Preventive Services Task Force recommendation statement. Ann Intern Med 164(4): 279-296

28. Oeffinger KC, Fontham ETH, Etzioni R et al (2015) Breast cancer screening for women at average risk: 2015 guideline update from the American Cancer Society. JAMA 314(15):1599-1614. https:// doi.org/10.1001/jama.2015.12783

29. The Canadian Task Force on Preventive Health Care (2011) Recommendations on screening for breast cancer in average-risk women aged 40-74 years. Can Med Assoc J 183(17):1991-2001. https://doi.org/10.1503/cmaj.110334

30. Lauby-Secretan B, Scoccianti C, Loomis D et al (2015) Breastcancer screening: viewpoint of the IARC Working Group. N Engl J Med 372(24):2353-2358

31. Moyer VA (2012) Screening for cervical cancer: U.S. preventive services task force recommendation statement. Ann Intern Med 156(12):880. https://doi.org/10.7326/0003-4819-156-12201206190-00424

32. Saslow D, Solomon D, Lawson HW et al (2012) American Cancer Society, American Society for Colposcopy and Cervical Pathology, and American Society for Clinical Pathology screening guidelines for the prevention and early detection of cervical cancer. Am J Clin Pathol 137(4):516-542. https://doi.org/10.1309/ AJCPTGD94EVRSJCG

33. Canadian Task Force on Preventive Health Care (2013) Recommendations on screening for cervical cancer. Can Med Assoc J 185(1):35-45. https://doi.org/10.1503/cmaj.121505

34. Bénard F, Barkun AN, Martel M, von Renteln D (2018) Systematic review of colorectal cancer screening guidelines for average-risk adults: summarizing the current global recommendations. World J Gastroenterol 24(1):124-138. https://doi.org/10. 3748/wjg.v24.i1.124

35. World Health Organization (2005) Cervix cancer screening. Available from: http://www.myilibrary.com?id=73529, accessed 14 November 2018

36. Dowling EC, Klabunde C, Patnick J, Ballard-Barbash R, for The International Cancer Screening Network (ICSN). Breast and cervical cancer screening programme implementation in 16 countries. J Med Screen 2010;17(3):139-146. https://doi.org/10.1258/ jms.2010.010033

37. Williams JH, Carter SM, Rychetnik L (2014) 'Organised' cervical screening 45 years on: how consistent are organised screening practices? Eur J Cancer 50(17):3029-3038. https://doi.org/10. 1016/j.ejca.2014.09.005

38. Benson VS, Patnick J, Davies AK, Nadel MR, Smith RA, Atkin WS (2008) Colorectal cancer screening: a comparison of 35 initiatives in 17 countries: worldwide colorectal Cancer screening. Int J Cancer 122(6):1357-1367. https://doi.org/10.1002/ijc.23273

39. Schreuders EH, Ruco A, Rabeneck L et al (2015) Colorectal cancer screening: a global overview of existing programmes. Gut 64(10):1637-1649. https://doi.org/10.1136/gutjnl-2014-309086

40. Levin TR, Jamieson L, Burley DA, Reyes J, Oehrli M, Caldwell C (2011) Organized colorectal cancer screening in integrated health care systems. Epidemiol Rev 33(1):101-110. https://doi.org/10. 1093/epirev/mxr007

41. Redelmeier DA, Tan SH, Booth GL (1998) The treatment of unrelated disorders in patients with chronic medical diseases. N Engl J Med 338(21):1516-1520. https://doi.org/10.1056/ NEJM199805213382106

42. Grant RW, Pirraglia PA, Melgs JB, Singer DE (2004) Trends in complexity of diabetes care in the United States from 1991 to 2000. Arch Intern Med 164(10):1134-1139. https://doi.org/10. 1001/archinte.164.10.1134 
43. Sinnott C, Mc Hugh S, Browne J, Bradley C (2013) GPs' perspectives on the management of patients with multimorbidity: systematic review and synthesis of qualitative research. BMJ Open 3(9): e003610. https://doi.org/10.1136/bmjopen-2013-003610

44. Jaen CR, Stange KC, Nutting PA (1994) Competing demands of primary care: a model for the delivery of clinical preventive services. J Fam Pract 38(2):166-174

45. Decker SL, Burt CW, Sisk JE (2009) Trends in diabetes treatment patterns among primary care providers. J Ambulatory Care Manage 32(4):333-341. https://doi.org/10.1097/JAC. 0b013e3181ba6e9e

46. O'Connor AM, Perrault DJ (1995) Importance of physician's role highlighted in survey of women's breast screening practices. Can J Public Health Rev Can Santé Publique 86(1):42-45

47. Grady KE, Lemkau JP, McVay JM, Reisine ST (1992) The importance of physician encouragement in breast cancer screening of older women. Prev Med 21(6):766-780. https://doi.org/10.1016/ 0091-7435(92)90083-T

48. Moher D, Liberati A, Tetzlaff J, Altman DG, for the PRISMA group (2009) Preferred reporting items for systematic reviews and meta-analyses: the PRISMA statement. BMJ 339:b2535. https://doi.org/10.1136/bmj.b2535

49. Liberati A, Altman DG, Tetzlaff J et al (2009) The PRISMA statement for reporting systematic reviews and meta-analyses of studies that evaluate healthcare interventions: explanation and elaboration. BMJ 339:b2700. https://doi.org/10.1136/bmj.b2700

50. Stroup DF (2000) Meta-analysis of observational studies in epidemiology: a proposal for reporting. JAMA 283(15):2008. https:// doi.org/10.1001/jama.283.15.2008

51. Shamseer L, Moher D, Clarke M et al (2015) Preferred reporting items for systematic review and meta-analysis protocols (PRISMA-P) 2015: elaboration and explanation. BMJ 349: g7647. https://doi.org/10.1136/bmj.g7647

52. Moher D, Stewart L, Shekelle P (2016) Implementing PRISMAP: recommendations for prospective authors. Syst Rev 5(1):15. https://doi.org/10.1186/s13643-016-0191-y

53. Terret C, Castel-Kremer E, Albrand G, Droz JP (2009) Effects of comorbidity on screening and early diagnosis of cancer in elderly people. Lancet Oncol 10(1):80-87. https://doi.org/10.1016/ S1470-2045(08)70336-X

54. Wools A, Dapper EA, de Leeuw JRJ (2016) Colorectal cancer screening participation: a systematic review. Eur J Pub Health 26(1):158-168. https://doi.org/10.1093/eurpub/ckv148

55. Diaz A, Kang J, Moore SP et al (2017) Association between comorbidity and participation in breast and cervical cancer screening: a systematic review and meta-analysis. Cancer Epidemiol 47: 7-19. https://doi.org/10.1016/j.canep.2016.12.010

56. Bramer WM, Giustini D, de Jonge GB, Holland L, Bekhuis T (2016) De-duplication of database search results for systematic reviews in EndNote. J Med Libr Assoc 104(3):240-243. https:// doi.org/10.3163/1536-5050.104.3.014

57. Higgins JPT, Green S (eds) (2011) Cochrane handbook for systematic reviews of interventions. Version 5.1.0 [updated March 2011]. The Cochrane Collaboration; 2011. Available from: http://handbook.Cochrane.org, accessed 25 February 2019

58. Wells GA, Shea B, O'Connell D, et al. (2019) The Newcastle-Ottawa Scale (NOS) for assessing the quality of nonrandomised studies in meta-analyses. Available from http://www.ohri.ca/programs/clinical epidemiology/oxford.asp, accessed 25 February 2019

59. Greiner KA, Daley CM, Epp A, James A, Yeh H-W, Geana M et al (2014) Implementation intentions and colorectal screening. Am J Prev Med 47(6):703-714. https://doi.org/10.1016/j.amepre.2014.08.005

60. Herzog R, Álvarez-Pasquin MJ, Díaz C, Del Barrio JL, Estrada JM, Gil Á (2013) Are healthcare workers' intentions to vaccinate related to their knowledge, beliefs and attitudes? A systematic review. Available from http://bmcpublichealth.biomedcentral. com/articles/10.1186/1471-2458-13-154, accessed 26 February 2019

61. DerSimonian R, Laird N (1986) Meta-analysis in clinical trials. Control Clin Trials 7(3):177-188. https://doi.org/10.1016/01972456(86)90046-2

62. Barros AJ, Hirakata VN (2003) Alternatives for logistic regression in cross-sectional studies: an empirical comparison of models that directly estimate the prevalence ratio. Available from http:// bmcmedresmethodol.biomedcentral.com/articles/10.1186/14712288-3-21, accessed 26 February 2019

63. Tamhane AR, Westfall AO, Burkholder GA, Cutter GR (2016) Prevalence odds ratio versus prevalence ratio: choice comes with consequences: prevalence odds ratio versus prevalence ratio. Stat Med 35(30):5730-5735. https://doi.org/10.1002/sim.7059

64. Thompson ML, Myers JE, Kriebel D (1998) Prevalence odds ratio or prevalence ratio in the analysis of cross sectional data: what is to be done? Occup Environ Med 55(4):272-277. https://doi.org/10. 1136/oem.55.4.272

65. Jensen LF, Pedersen AF, Andersen B, Vestergaard M, Vedsted P (2015) Non-participation in breast cancer screening for women with chronic diseases and multimorbidity: a population-based cohort study. Available from: http://www.biomedcentral.com/14712407/15/798, accessed 14 November 2018

66. Miller EA, Tarasenko YN, Parker JD, Schoendorf KC (2014) Diabetes and colorectal cancer screening among men and women in the USA: National Health Interview Survey: 2008, 2010. Cancer Causes Control 25(5):553-560. https://doi.org/10.1007/ s10552-014-0360-z

67. Dickersin K (2002) Systematic reviews in epidemiology: why are we so far behind? Int J Epidemiol 31(1):6-12. https://doi.org/10. 1093/ije/31.1.6

68. Egger M, Schneider M, Smith GD (1998) Meta-analysis spurious precision? Meta-analysis of observational studies. BMJ 316(7125):140-144. https://doi.org/10.1136/bmj.316.7125.140

69. Cummings $P$ (2009) The relative merits of risk ratios and odds ratios. Arch Pediatr Adolesc Med 163(5):438. https://doi.org/10. 1001/archpediatrics.2009.31

70. Oluyemi AO, Welch AR, Yoo LJ, Lehman EB, McGarrity TJ, Chuang CH (2014) Colorectal cancer screening in high-risk groups is increasing, although current smokers fall behind: CRC screening in high-risk groups. Cancer 120(14):2106-2113. https:// doi.org/10.1002/cncr.28707

71. Beckman TJ, Cuddihy RM, Scheitel SM, Naessens JM, Killian JM, Pankratz VS (2001) Screening mammogram utilization in women with diabetes. Diabetes Care 24(12):2049-2053. https:// doi.org/10.2337/diacare.24.12.2049

72. Blustein J, Weiss LJ (1998) The use of mammography by women aged 75 and older: factors related to health, functioning, and age. J Am Geriatr Soc 46(8):941-996. https://doi.org/10.1111/j.15325415.1998.tb02746.x

73. Chan W, Yun L, Austin PC et al (2014) Impact of socio-economic status on breast cancer screening in women with diabetes: a population-based study. Diabet Med 31(7):806-812. https://doi. org/10.1111/dme.12422

74. Katz D, Tengekyon AJ, Kahan NR, Calderon-Margalit R (2018) Patient and physician characteristics affect adherence to screening mammography: a population-based cohort study. PLoS One.13(3):e0194409, https://doi.org/10.1371/journal.pone. 0194409

75. Lipscombe LL, Hux JE, Booth GL (2005) Reduced screening mammography among women with diabetes. Arch Intern Med 165(18):2090-2095. https://doi.org/10.1001/archinte.165.18. 2090

76. Banks E, Beral V, Cameron R, et al. (2002) Comparison of various characteristics of women who do and do not attend for breast cancer screening. Available from http://breast-cancer-research. 
biomedcentral.com/articles/10.1186/bcr418, accessed 14 November 2018

77. El Bcheraoui C, Basulaiman M, Wilson S, et al. (2015) Breast cancer screening in Saudi Arabia: free but almost no takers. PLoS One: 10(3):e0119051. https://doi.org/10.1371/journal.pone.0119051

78. Sanderson M, Lipworth L, Han X et al (2014) Mammography use among women with and without diabetes: results from the southern community cohort study. J Epidemiol Glob Health 4(3):223230. https://doi.org/10.1016/j.jegh.2014.03.001

79. Abdullah NN, Daud S, Al-Kubaisy W, Saari IS, Saad SR (2016) Cervical cancer screening after 50: near extinction? Eur J Obstet Gynecol Reprod Biol 206:136-140. https://doi.org/10.1016/j. ejogrb.2016.09.011

80. Richard A, Rohrmann S, Schmid SM et al (2015) Lifestyle and health-related predictors of cervical cancer screening attendance in a Swiss population-based study. Cancer Epidemiol 39(6):870 876. https://doi.org/10.1016/j.canep.2015.09.009

81. Wernli KJ, Hubbard RA, Johnson E et al (2014) Patterns of colorectal cancer screening uptake in newly eligible men and women. Cancer Epidemiol Biomark Prev 23(7):1230-1237. https://doi. org/10.1158/1055-9965.EPI-13-1360

82. Brittain K, Murphy VP (2015) Sociocultural and health correlates related to colorectal cancer screening adherence among urban African Americans. Cancer Nurs 38(2):118-124. https://doi.org/ 10.1097/NCC.0000000000000157

83. Porter NR, Eberth JM, Samson ME, Garcia-Dominic O, Lengerich EJ, Schootman M (2012) Diabetes status and being up-to-date on colorectal cancer screening. Behavioral Risk Factor Surveillance System. 2016. Available from http://www.cdc.gov/pcd/issues/ 2016/15_0391.htm, accessed 14 November 2018

84. Singh H, Bernstein CN, Samadder JN, Ahmed R (2015) Screening rates for colorectal cancer in Canada: a cross-sectional study. CMAJ Open 3(2):E149-E157. https://doi.org/10.9778/cmajo.20140073

85. Bell RA, Shelton BJ, Paskett ED (2001) Colorectal cancer screening in North Carolina: associations with diabetes mellitus and demographic and health characteristics. Prev Med 32(2):163167. https://doi.org/10.1006/pmed.2000.0785

86. Kiefe CI, Funkhouser E, Fouad MN, May DS (1998) Chronic disease as a barrier to breast and cervical cancer screening. J Gen Intern Med 13(6):357-365. https://doi.org/10.1046/j.15251497.1998.00115.x

87. Chuck KW, Hwang M, Choi KS, Suh M, Jun JK, Park B (2017) Cancer screening rate in people with diabetes in the Korean population: results from the Korea National Health and Nutrition Examination Survey 2007-2009. Epidemiol Health 39: e2017036. https://doi.org/10.4178/epih.e2017036

88. Constantinou P, Dray-Spira R, Menvielle G (2016) Cervical and breast cancer screening participation for women with chronic conditions in France: results from a national health survey. Available from http://bmccancer.biomedcentral.com/articles/10.1186/ s12885-016-2295-0, accessed 14 November 2018

89. Coughlin SS, Uhler RJ, Hall HI, Briss PA (2004) Nonadherence to breast and cervical cancer screening: what are the linkages to chronic disease risk? Prev Chronic Dis 1(1):1-15

90. Marshall JG, Cowell JM, Campbell ES, McNaughton DB (2010) Regional variations in cancer screening rates found in women with diabetes. Nurs Res 59(1):34-41. https://doi.org/10.1097/NNR. 0b013e3181c3bd07

91. López-de-Andrés A, Martin-Lopez R, Hernández-Barrera V et al (2010) Predictors of breast and cervical cancer screening in a Spanish metropolitan area. J Women's Health 19(9):1675-1681. https://doi.org/10.1089/jwh.2009.1828

92. Jimenez-Garcia R, Hernandez-Barrera V, Carrasco-Garrido P, Gil A (2009) Prevalence and predictors of breast and cervical cancer screening among Spanish women with diabetes. Diabetes Care 32(8):1470-1472. https://doi.org/10.2337/dc09-0479
93. Martinez-Huedo MA, Lopez de Andres A, Hernandez-Barrera V, Carrasco-Garrido P, Martinez Hernandez D, Jiménez-Garcia R (2012) Adherence to breast and cervical cancer screening in Spanish women with diabetes: associated factors and trend between 2006 and 2010. Diabetes Metab 38(2):142-148. https:// doi.org/10.1016/j.diabet.2011.09.007

94. McBean AM, Yu X (2007) The underuse of screening services among elderly women with diabetes. Diabetes Care 30(6):14661472. https://doi.org/10.2337/dc06-2233

95. Heflin MT, Oddone EZ, Pieper CF, Burchett BM, Cohen HJ (2002) The effect of comorbid illness on receipt of cancer screening by older people. J Am Geriatr Soc 50(10):1651-1658. https:// doi.org/10.1046/j.1532-5415.2002.50456.x

96. Fleming ST, Love MM, Bennett K (2011) Diabetes and cancer screening rates among Appalachian and non-Appalachian residents of Kentucky. J Am Board Fam Med 24(6):682-692. https://doi.org/10.3122/jabfm.2011.06.110094

97. Fontana SA, Baumann LC, Helberg C, Love RR (1997) The delivery of preventive services in primary care practices according to chronic disease status. Am J Public Health 87(7):1190-1196. https://doi.org/10.2105/AJPH.87.7.1190

98. Hsia J, Kemper E, Kiefe C et al (2000) The importance of health insurance as a determinant of cancer screening: evidence from the Women's Health Initiative. Prev Med 31(3):261-270. https://doi. org/10.1006/pmed.2000.0697

99. Jimenez-Trujillo I, Jiménez-García R, Esteban-Hernández J et al (2015) Predictors of adherence to multiple clinical preventive recommendations among adults with diabetes in Spain. PLoS One 10(6):e0131844. https://doi.org/10.1371/journal.pone.0131844

100. Karathanasi I, Kamposioras K, Cortinovis I et al (2009) Moving ahead in diabetics' cancer screening; food for thought from the Hellenic experience. Eur J Cancer Care (Engl) 18(3):255-263. https://doi.org/10.1111/j.1365-2354.2007.00858.x

101. Liu BY, O'Malley J, Mori M et al (2014) The association of type and number of chronic diseases with breast, cervical, and colorectal cancer screening. J Am Board Fam Med 27(5):669-681. https://doi.org/10.3122/jabfm.2014.05.140005

102. Owens MD, Beckles GLA, Ho KK-Y, Gorrell P, Brady J, Kaftarian JS (2008) Women with diagnosed diabetes across the life stages: underuse of recommended preventive care services. J Women's Health 17(9):1415-1423. https://doi.org/10.1089/jwh.2008.1125

103. Zhao G, Ford ES, Ahluwalia IB, Li C, Mokdad AH (2009) Prevalence and trends of receipt of cancer screenings among US women with diagnosed diabetes. J Gen Intern Med 24(2):270 275. https://doi.org/10.1007/s11606-008-0858-8

104. Yuan X, Liu T, Wu L, Zou Z-Y, Li C. Validity of self-reported diabetes among middle-aged and older Chinese adults: the China health and retirement longitudinal study. BMJ Open 2015;5(4):e006633e006633, https://doi.org/10.1136/bmjopen-2014-006633

105. Pastorino S, Richards M, Hardy R et al (2015) Validation of selfreported diagnosis of diabetes in the 1946 British birth cohort. Prim Care Diabetes 9(5):397-400. https://doi.org/10.1016/j.pcd. 2014.05.003

106. Espelt A, Goday A, Franch J, Borrell C (2012) Validity of selfreported diabetes in health interview surveys for measuring social inequalities in the prevalence of diabetes: Table 1. J Epidemiol Community Health 66(7):e15-e15. https://doi.org/10.1136/jech. 2010.112698

107. Martin LM, Leff M, Calonge N, Garrett C, Nelson DE (2000) Validation of self-reported chronic conditions and health services in a managed care population. Am J Prev Med 18(3):215-218. https://doi.org/10.1016/S0749-3797(99)00158-0

108. Schneider ALC, Pankow JS, Heiss G, Selvin E (2012) Validity and reliability of self-reported diabetes in the atherosclerosis risk in communities study. Am J Epidemiol 176(8):738-743. https:// doi.org/10.1093/aje/kws156 
109. Howard M, Agarwal G, Lytwyn A (2009) Accuracy of self-reports of Pap and mammography screening compared to medical record: a meta-analysis. Cancer Causes Control 20(1):1-13. https://doi. org/10.1007/s10552-008-9228-4

110. Ferrante JM, Ohman-Strickland P, Hahn KA et al (2008) Selfreport versus medical records for assessing cancer-preventive services delivery. Cancer Epidemiol Biomark Prev 17(11):29872994. https://doi.org/10.1158/1055-9965.EPI-08-0177

111. Gordon NP, Hiatt RA, Lampert DI (1993) Concordance of selfreported data and medical record audit for six cancer screening procedures. J Natl Cancer Inst 85(7):566-570. https://doi.org/10. 1093/jnci/85.7.566

112. Lysy Z, Booth GL, Shah BR, Austin PC, Luo J, Lipscombe LL (2013) The impact of income on the incidence of diabetes: a population-based study. Diabetes Res Clin Pract 99(3):372-379. https://doi.org/10.1016/j.diabres.2012.12.005

113. Singh SM, Paszat LF, Li C, He J, Vinden C, Rabeneck L (2004) Association of socioeconomic status and receipt of colorectal cancer investigations: a population-based retrospective cohort study. Can Med Assoc J 171(5):461-465. https://doi.org/10.1503/cmaj. 1031921

114. Eckstrom E, Feeny DH, Walter LC, Perdue LA, Whitlock EP (2013) Individualizing cancer screening in older adults: a narrative review and framework for future research. J Gen Intern Med 28(2):292-298. https://doi.org/10.1007/s11606-012-2227-x

115. Sterne JAC, Sutton AJ, Ioannidis JPA et al (2011) Recommendations for examining and interpreting funnel plot asymmetry in metaanalyses of randomised controlled trials. BMJ 343:d4002. https:// doi.org/10.1136/bmj.d4002

116. Morrison A, Polisena J, Husereau D et al (2012) The effect of English-language restriction on systematic review-based metaanalyses: a systematic review of empirical studies. Int J Technol Assess Health Care 28(02):138-144. https://doi.org/10.1017/ S0266462312000086

117. Taksler GB, Pfoh ER, Stange KC, Rothberg MB (2018) Association between number of preventive care guidelines and preventive care utilization by patients. Am J Prev Med 55(1):1-10. https://doi.org/ 10.1016/j.amepre.2018.03.011

118. Ostbye T, Yarnall KS, Krause KM, Pollak KI, Gradison M, Michener JL (2005) Is there time for management of patients with chronic diseases in primary care? Ann Fam Med 3(3):209-214. https://doi.org/10.1370/afm.310

119. Streja DA, Rabkin SW (1999) Factors associated with implementation of preventive care measures in patients with diabetes mellitus. Arch Intern Med 159(3):294-302. https://doi.org/10. 1001/archinte.159.3.294

120. Cheung A, Stukel TA, Alter DA et al (2017) Primary care physician volume and quality of diabetes care: a population-based cohort study. Ann Intern Med 166(4):240. https://doi.org/10.7326/ M16-1056

121. Ioannou GN, Chapko MK, Dominitz JA (2003) Predictors of colorectal cancer screening participation in the United States. Am J Gastroenterol 98(9):2082-2091. https://doi.org/10.1111/j.15720241.2003.07574.x

122. Gancayco J, Soulos PR, Khiani Vet al (2013) Age-based and sexbased disparities in screening colonoscopy use among Medicare beneficiaries. J Clin Gastroenterol 47(7):630-636. https://doi.org/ 10.1097/MCG.0b013e31828345c8

123. Klabunde C, Blom J, Bulliard J-L et al (2015) Participation rates for organized colorectal cancer screening programmes: an international comparison. J Med Screen 22(3):119-126. https://doi.org/ 10.1177/0969141315584694

124. Sabatino SA, Lawrence B, Elder R et al (2012) Effectiveness of interventions to increase screening for breast, cervical, and colorectal cancers. Am J Prev Med 43(1):97-118. https://doi.org/ 10.1016/j.amepre.2012.04.009

125. Duffy SW, Myles JP, Maroni R, Mohammad A (2017) Rapid review of evaluation of interventions to improve participation in cancer screening services. J Med Screen 24(3):127-145. https:// doi.org/10.1177/0969141316664757

126. van Rossum LG, van Rijn AF, Laheij RJ et al (2008) Random comparison of Guaiac and immunochemical fecal occult blood tests for colorectal cancer in a screening population. Gastroenterology 135(1): 82-90. https://doi.org/10.1053/j.gastro.2008.03.040

127. Coronado GD, Petrik AF, Vollmer WM et al (2018) Effectiveness of a mailed colorectal cancer screening outreach program in community health clinics: the STOP CRC cluster randomized clinical trial. JAMA Intern Med 178(9):1174. https://doi.org/10.1001/ jamainternmed.2018.3629

128. Verdoodt F, Jentschke M, Hillemanns P, Racey CS, Snijders PJF, Arbyn M (2015) Reaching women who do not participate in the regular cervical cancer screening programme by offering selfsampling kits: a systematic review and meta-analysis of randomised trials. Eur J Cancer 51(16):2375-2385. https://doi. org/10.1016/j.ejca.2015.07.006

129. Dijkstra MG, van Zummeren M, Rozendaal L et al (2016) Safety of extending screening intervals beyond five years in cervical screening programmes with testing for high risk human papillomavirus: 14 year follow-up of population based randomised cohort in the Netherlands. BMJ 355:i4924

130. Nelson EJ, Maynard BR, Loux T, Fatla J, Gordon R, Arnold LD (2017) The acceptability of self-sampled screening for HPV DNA: a systematic review and meta-analysis. Sex Transm Infect 93(1): 56-61. https://doi.org/10.1136/sextrans-2016-052609

131. Rees I, Jones D, Chen H, Macleod U (2018) Interventions to improve the uptake of cervical cancer screening among lower socioeconomic groups: a systematic review. Prev Med 111:323335. https://doi.org/10.1016/j.ypmed.2017.11.019

132. Beeker C, Kraft JM, Southwell BG, Jorgensen CM (2000) Colorectal cancer screening in older men and women: qualitative research findings and implications for intervention. J Community Health 25(3):263-278. https://doi.org/10.1023/A: 1005104406934

133. Friedemann-Sánchez G, Griffin JM, Partin MR (2007) Gender differences in colorectal cancer screening barriers and information needs. Health Expect 10(2):148-160. https://doi.org/10.1111/j. 1369-7625.2006.00430.x

134. Elston Lafata J, Martin S, Morlock R, Divine G, Xi H (2001) Provider type and the receipt of general and diabetes-related preventive health services among patients with diabetes. Med Care 39(5):491-499. https://doi.org/10.1097/00005650-200105000-00009

135. Horný M, Glover W, Gupte G, Saraswat A, Vimalananda V, Rosenzweig J (2017) Patient navigation to improve diabetes outpatient care at a safety-net hospital: a retrospective cohort study. Available from: https://bmchealthservres.biomedcentral.com/articles/10.1186/ s12913-017-2700-7, accessed 14 November 2018

136. Nayor J, Maniar S, Chan WW (2017) Appointment-keeping behaviors and procedure day are associated with colonoscopy attendance in a patient navigator population. Prev Med 97:8-12. https://doi.org/10.1016/j.ypmed.2016.12.022

Publisher's note Springer Nature remains neutral with regard to jurisdictional claims in published maps and institutional affiliations. 